\title{
Error Compensation for Thermally Induced Errors on a Machine Tool
}

\author{
D. A. Krulewich
}

November 8, 1996






\section{DISCLAIMER}

This document was prepared as an account of work sponsored by an agency of the United States Government. Neither the United States Government nor the University of California nor any of their employees, makes any warranty, express or implied, or assumes any legal liability or responsibility for the accuracy, completeness, or usefulness of any information, apparatus, product, or process disclosed, or represents that its use would not infringe privately owned rights. Reference herein to any specific commercial product, process, or service by trade name, trademark, manufacturer, or otherwise, does not necessarily constitute or imply its endorsement, recommendation, or favoring by the United States Government or the University of California. The views and opinions of authors expressed herein do not necessarily state or reflect those of the United States Government or the University of California, and shall not be used for advertising or product endorsement purposes.

This report has been reproduced directly from the best available copy.

Available to DOE and DOE contractors from the Office of Scientific and Technical Information P.O. Box 62, Oak Ridge, TN 37831

Prices available from (615) 576-8401, FTS 626-8401

Available to the public from the

National Technical Information Service

U.S. Department of Commerce

5285 Port Royal Rd.,

Springfield, VA 22161 


\title{
ERROR COMPENSATION FOR THERMALLY INDUCED ERRORS ON A MACHINE TOOL
}

\author{
Debra A. Krulewich \\ Engineer \\ Mechanical Engineering Department \\ Materials and Manufacturing Engineering Division \\ Precision Systems and Manufacturing Group \\ Lawrence Livermore National Laboratory \\ University of California \\ Livermore, CA 94551
}

November 8, 1996 


\section{Abstract}

Heat flow from both internal and external sources and temperature of the environment create machine deformations, resulting in positioning errors between the tool and workpiece. If the error can be predicted from a reasonable number of inputs, it can then be removed in real time by the machine controller. Although much research is currently being performed in the field of thermal error compensation, there is no industrially accepted method. There are many possible input-output correlations, and the models can be established empirically, analytically, or by some combination of these. I have selected a simple model that linearly relates discrete temperature measurements to the deflection. The largest barrier to the success of this type of model is how to (1) locate the temperature sensors and (2) determine the number of required temperature sensors so the model is robust enough to perform under varying operating conditions. This research develops a method to determine the number and location of temperature measurements. The approach assumes that adequate knowledge of the temperature distribution completely determines the deflection at any instant in time, so the model is not time dependent. An advantage to this approach is that warm-up and cool down situations can be represented by the same model as steady state conditions. Furthermore, the model is based on the analytical solution to thermally induced deflections.

\section{Introduction}

Machine deformation is caused by a varying temperature field throughout the machine due to changing operating conditions. The cause-effect relationship is pictorially represented in Figure 1. The most complex model first relates the operating conditions to the imposed heat flows. The heat flows are used to determine the temperature field and the temperature field is then used to determine deformations. Finite element analysis is a useful tool to determine the model. However, in practice this method has not been successful because the output is very dependent on the particular boundary conditions.

Simpler models relate experimentally measured deformations to measured inputs. The form of the model can be analytically determined or purely empirical. There are three types of inputs that can be considered: (1) operating conditions, (2) heat flows, and (3) temperature field. A model based on heat flows or temperature fields measures discrete locations. Difficulties with these approaches are (1) where to measure the input and (2) how many inputs are required. The number and location of inputs may vary as the operating conditions change. A model based on operating conditions is usually very complex. Furthermore, models using either heat flow or operating conditions as inputs are time dependent due to the thermal capacitance of the machine structure. 


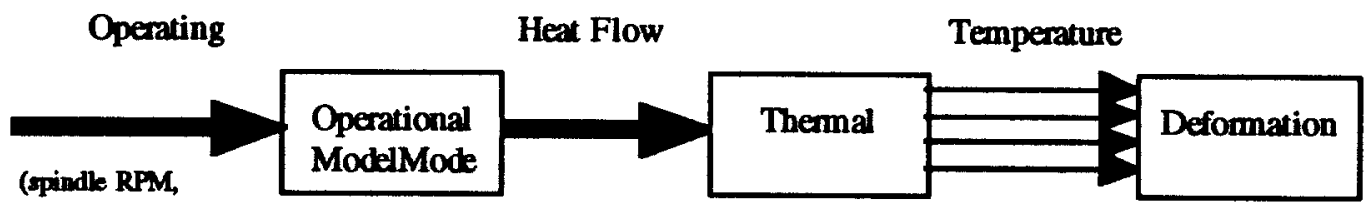

Figure 1: Causes of Thermal Deformation

Possibly because the last mentioned difficulty, most current research is attempting to capture the temperature profile. Given the complete temperature distribution through the machine, the tool point error can be precisely determined with no time dependencies. A variety of approaches are being employed to determine optimal temperature sensor locations and the number of required temperature sensors. The focus of this research is to develop a procedure for determining the optimum number and location of temperature sensors that lead to a robust model.

\section{Current Methods}

The basic approaches include finite element analysis (FEA), which is purely analytical, and both neural network and statistical approaches, which are purely empirical. Combinations of empirical and theoretical approaches also exist, where an empirical approach is taken to determine the temperature distribution and a theoretical approach is taken to determine the resulting deflection. Purely analytical approaches have not been successful since the boundary conditions are not typically known.

The simplest empirical approach attempts to relate selected measured temperatures to the tool point deflection. The largest barrier to the success of these methods is how to (1) locate the temperature sensors and (2) determine the number of required temperature sensors. Some researchers have used engineering expertise to locate temperature sensors near thermal sources. However, the relationship between the source temperatures and tool point deflection is often non-linear. Therefore a large amount of data is required to adequately train the model. Other researchers have placed many temperature sensors on the machine and have used either statistics or neural networks to determine the optimum subset of sensors. The most popular approach is a combination, where engineering expertise is used to place more sensors than the system requires and then statistics or a neural network is used to determine the optimum location and number of sensors. Some researchers have used as many as 100 temperature sensors on the machine to determine the optimum subset. 
Researchers usually assume that this process must be performed only once for a given machine configuration and then the results can be applied to any other machine of similar design. However, the process of selection usually requires large amounts of data, temperature sensors, and time and is often not practical to the common machine user. Furthermore, it is not apparent that the optimum sensors for one particular machine are the same optimum sensors for another machine in a different operating environment.

For these reasons, this work focuses on developing a method of determining the number and location of temperature measurements. This approach assumes that knowledge of the temperature distribution completely determines the deflection at any instant in time. Therefore, the point is to determine the number and location of temperature measurements required to represent the machine deformation under varying operating conditions. An advantage to this approach is that warm-up and cool-down situations can be represented by the same model as steady state conditions. Furthermore, a model has been selected that is based on the physics of the system.

\section{Technical Approach}

The heart of this approach is based on the assumption that a temperature distribution in a particular region on a machine can be estimated by a polynomial. As boundary conditions change, the coefficients of the polynomial change, but the order of the polynomial is always equal to or less than a finite value. The model must have the ability to track the error under varying boundary conditions. This includes warm-up and cool-down cycles as well as changing velocities and changing environmental conditions. To achieve this robustness, the model must be independent of the coefficients of the polynomial. An approach has been chosen where the location and number of sensors are dependent on the order of the polynomial but not on the actual coefficients of the polynomial. This will produce a robust model that has good tracking capability. Furthermore, less data is required to fit this model and the model will have better extrapolating abilities.

\section{Simplified one-dimensional heat flow}

The one-dimensional deflection caused by a temperature distribution is

$$
\Delta x=\int_{0}^{L} \alpha(x) T(x) d x=\alpha \int_{0}^{L} T(x) d x
$$

where

$$
\begin{aligned}
& \Delta x=\text { deflection in the } \mathrm{x} \text { direction, } \\
& \alpha(x)=\text { coefficient of thermal expansion as a function of } \mathrm{x}, \\
& T(x)=\text { temperature distribution as a function of } \mathrm{x}, \text { and } \\
& L \quad=\text { length in the } \mathrm{x} \text { direction. }
\end{aligned}
$$


For a given region, assume that the thermal coefficient of expansion is constant in $x$. The estimate of the deflection in $\mathbf{x}$ can then be thought of as a numerical integration problem, where the integral is numerically approximated as

$$
\int_{0}^{L} T(x) d x \approx\left[w_{1} T\left(x_{1}\right)+w_{2} T\left(x_{2}\right)+\ldots+w_{n} T\left(x_{n}\right)\right]=\sum_{i=1}^{n} w_{i} T\left(x_{i}\right),
$$

so the numerical approximation of the deflection is

$$
\Delta x \approx \alpha\left[w_{1} T\left(x_{1}\right)+w_{2} T\left(x_{2}\right)+\ldots+w_{n} T\left(x_{n}\right)\right]=\alpha \sum_{i=1}^{n} w_{i} T\left(x_{i}\right) .
$$

There are many common forms of numerical integration such as the Forward and Backward Cauchy Euler methods. However, in order to integrate the above equation exactly with the minimum number of points, Gaussian integration is used. First, assume the temperature distribution can adequately be represented by a polynomial of order $k$,

$$
T(x) \approx a_{0}+a_{1} x+a_{2} x^{2}+\ldots+a_{k} x^{k}=\sum_{j=0}^{k} a_{j} x^{j}
$$

Then the deflection in $\mathbf{x}$ is approximately proportional to the integral of the temperature distribution in Equation (3). Substituting (4) into (1) and integrating results in,

$$
\left.\Delta x \approx \alpha\left(a_{0} x+\frac{a_{1} x^{2}}{2}+\frac{a_{2} x^{3}}{3}+\ldots+\frac{a_{n} x^{(n+1)}}{(n+1)}\right)\right|_{0} ^{L}=\alpha \sum_{j=0}^{k} \frac{a_{j} L^{(j+1)}}{(j+1)}
$$

Equation (5) is then set equal to (3),

$$
\Delta x \approx \alpha \sum_{i=1}^{n}\left[w_{i}\left(\sum_{j=0}^{k} a_{j} x_{i}^{j}\right)\right] \approx \alpha \sum_{j=0}^{k} \frac{a_{j} L^{(j+1)}}{(j+1)}
$$

Rearranging,

$$
\alpha \sum_{j=0}^{k} a_{j} \sum_{i=1}^{n}\left[w_{i} x_{i}^{j}\right] \approx \alpha \sum_{j=0}^{k} a_{j} \frac{L^{(j+1)}}{(j+1)}
$$

Since the polynomial coefficients are completely arbitrary, the terms in front of each coefficient on each side of Equation (7) can be equated, resulting in $k+1$ equations and $2 \mathrm{n}$ unknowns, where $n$ is the number of integration points and $k$ is the order of the polynomial. Therefore, the optimum number of integration points is

$$
n=\frac{k+1}{2}
$$

Canceling out like terms results in the following $k$ equations. 


$$
\sum_{i=1}^{n}\left[w_{i} x_{i}^{j}\right]=\frac{L^{(j+1)}}{(j+1)} ; j=0,1,2, \ldots, k
$$

Each individual equation is

$$
\begin{gathered}
\sum_{i=1}^{n} w_{i}=\frac{L}{2} ; j=0 \\
\sum_{i=1}^{n}\left[w_{i} x_{i}\right]=\frac{L^{2}}{2} ; j=1 \\
: \\
\vdots \\
\sum_{i=1}^{n}\left[w_{i} x_{i}^{n}\right]=\frac{L^{(n+1)}}{(n+1)} ; j=n
\end{gathered}
$$

The order of the polynomial can be determined by theoretical analysis such as FEA. Even simpler, the order of polynomial can be directly determined by the number of boundary conditions (heat sources and convection surfaces).

The procedure is to determine the order of polynomial that best represents the temperature field. Then based on the polynomial order and limits of integration, determine the optimum number and location of temperature sensors. Since the effective coefficient of expansion is not known, temperature data and resulting deformations are measured throughout the expected operating conditions. The appropriate weighting is determined using a least squares procedure. This linear equation can then be used to predict deformations from measured temperatures.

\section{Position dependent errors}

Some thermally induced errors are also position dependent. This is due to the fact that the position of the axes changes the effective structural loop between the tool point and workpiece. As an example, the pitch error of the $\mathrm{x}$ axis is not only dependent on temperature but also on the $x$ position. On the other hand, spindle axial growth is not dependent on the position of the axes since the entire spindle is always included in the structural loop. Up to this point, the proposed method is only applicable to position independent errors. This method can be extended to position dependent errors in the following way.

A similar numerical integration procedure is used for position dependent errors. However, since the limits of integration change for different axes positions, the location of temperature sensors cannot be dependent on the limits of integration as they were in the previous case. Instead, the procedure sets the temperature sensor locations, and the weights 
now become a function of position. As shown in Equation (8), there are still $k+1$ equations. However, the location of the temperature measurements are pre-set, so there are only $\mathbf{n}$ unknowns. Therefore, the optimum number of integration points is

$$
n=k+1 \text {. }
$$

As an example, consider a simplified first order temperature distribution where

$$
T(x)=a_{1} x+a_{0}, x \in\{0, L\} .
$$

According to Equation (13), this temperature distribution requires two discrete temperature measurements. First the locations of these two measurements are pre-set to specific values, $x_{1}$ and $x_{2}$. Plugging this into Equation (7) and integrating between 0 to an arbitrary value $\mathrm{x}$ results in

$$
\left[w_{1}\left(a_{1} x_{1}+a_{0}\right)+w_{2}\left(a_{1} x_{2}+a_{0}\right)\right]=a_{0} x+a_{1} \frac{x^{2}}{2} .
$$

The coefficients of the polynomial are completely arbitrary and the weight functions are not dependent on these coefficients. Relating terms containing each coefficient on the left hand side of Equation (14) to the right hand side results in two equations,

$$
\begin{gathered}
w_{1} x_{1}+w_{2} x_{2}=\frac{x^{2}}{2}, \\
w_{1}+w_{2}=x .
\end{gathered}
$$

Solving Equations (15) and (16) for the weights results in

$$
\begin{aligned}
& w_{1}=\frac{x^{2}-2 x_{2} x}{2\left(x_{1}-x_{2}\right)}=a x^{2}+b x, \\
& w_{2}=\frac{-x^{2}+2 x_{1} x}{2\left(x_{1}-x_{2}\right)}=c x^{2}+d x .
\end{aligned}
$$

The procedure is to set the location of the two sensors (for this first order example). Then temperature data and resulting deformations are measured throughout the expected operating conditions. Using a least squares procedure, the appropriate coefficients for the weights ( $a, b, c$, and $d$ in Equations (17) and (18)) are determined. This linear equation can then be used to predict deformations from measured temperatures.

As a general rule, the weight function contains terms from $x$ to $x^{k+1}$, where $k$ is the order of polynomial that adequately represents the temperature field.

\section{Multi-dimensional heat flow}

This procedure can be easily extended to multiple dimensions. For a complete $\mathbf{p}$ order polynomial in $\mathrm{d}$ dimensions, the number of terms in the polynomial is 


$$
m=\frac{(p+d) !}{p ! d !} .
$$

For example, a complete second order polynomial in three dimensions is

$$
T(x, y, z)=a_{0}+a_{1} x^{2}+a_{2} x+a_{3} y^{2}+a_{4} y+a_{5} z^{2}+a_{6} z+a_{7} x y+a_{8} y z+a_{9} x z .
$$

Equation (20) contains ten terms. According to Equation (19), the number of terms is

$$
m=\frac{(2+3) !}{2 ! 3 !}=10
$$

This temperature distribution will result in $m$ equations, one for each arbitrary coefficient. If the particular error is not position dependent, there are $(d+1)^{*} n$ unknowns, where $n$ is the number of temperature measurements. Therefore, the required number of temperature measurements is

$$
n \geq \frac{m}{d+1}=\frac{(p+d) !}{p !(d+1) !}
$$

For the complete second order polynomial in three dimensions, three temperature measurements are required. This results in twelve unknowns $\left(w_{1}, x_{1}, y_{1}, z_{1}, w_{2}, x_{2}, y_{2}, z_{2}\right.$, $\left.w_{3}, x_{3}, y_{3}, z_{3}\right)$. Two of the locations can be set arbitrarily and the remaining ten unknowns are found by solving the ten equations.

Conversely, if the error is position dependent, the position of the sensors are preset as explained in the previous section and the weight functions become a function of position. If the error is dependent on the position of only one axis, the $\mathbf{n}$ positions along that axis are pre-determined pre-set. Then the number of unknowns reduces by $n$, so the number of required sensors is

$$
n \geq \frac{m}{d}=\frac{(p+d) !}{p ! d ! d} .
$$

For the complete second order polynomial in three dimensions, four temperature measurements are required.

This option is more practical when designing a new machine where embedding the sensors into the machine structure is an option. If retrofitting an existing machine, this may not be an option. In this case, as more locations of the sensors are pre-determined, more sensors are required.

\section{Test Set-Up}

Two test set-ups have been designed. The purpose of the first set-up is to study this approach using a simple, one dimensional heat flow problem with a known, controlled heat source. The purpose of the second set-up is to apply this theory to an actual spindle. 
The first test stand consists of a hollow, $305 \mathrm{~mm}$ aluminum tube mounted vertically, shown in Figure 2. One end is attached to a granite block while the other end is free. A capacitance gage is used to measure growth at the free end. A total of nine thermistors are mounted along the length of the tube, and the temperature of the granite block along with ambient temperature are also monitored.

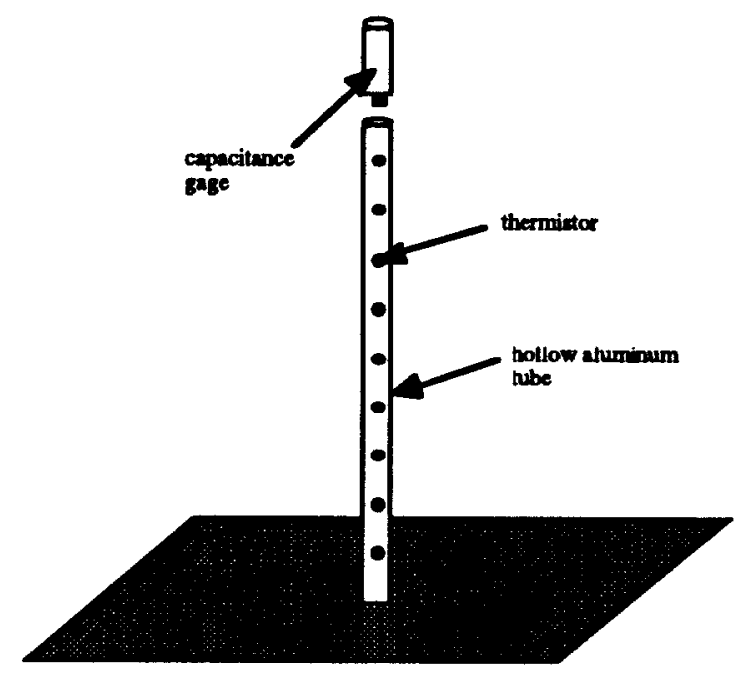

Figure 2: Test Set-Up 1

The second test stand consists of a horizontally mounted spindle attached to a granite block. The spindle has an integral motor with chilled water cooling around the motor. In this configuration, only axial growth was madeled because the radial growth and tilt were insignificant due to symmetry. Thermistors are mounted along the body of the spindle to measure the temperature distribution. The mandrel in the spindle is super invar to reduce its thermal growth. Differential eddy current sensors are used to measure radial growth and tilt while a capacitance gage is used to measure axial growth. The test set-up is shown in Figure 3. 


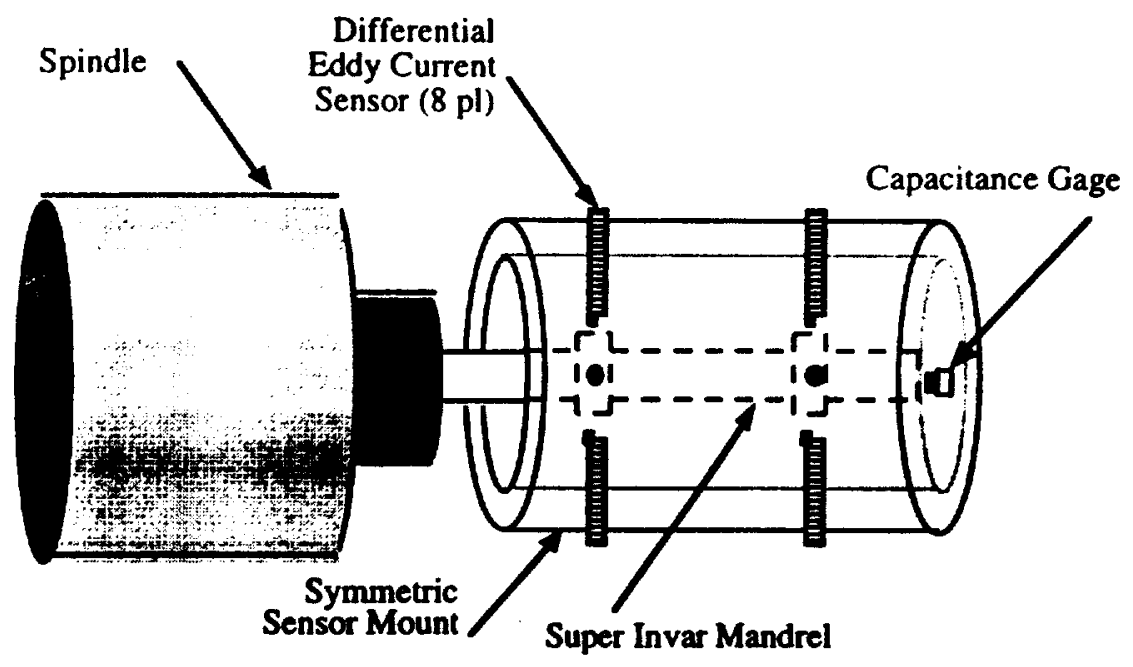

Figure 3: Test Set-Up 2

\section{Results}

\section{Test Set-Up 1 - Aluminum Tube}

Nine temperature sensors were placed along the length of the aluminum tube. $A$ thin wire with current running through it was used as a single point heat source. Axial growth was measured for the heat source at 8.75 " from the granite block. Temperature and growth measurements were taken when maximum current was applied for 20 minutes. Then the heat source was removed and data were taken for $\mathbf{2 0}$ more minutes while the aluminum tube cooled. The temperature profile could be represented by a third order polynomial. By Equation (6), two points are required for numerical integration.

Five additional sets of data were acquired for model verification, using equal or less current through the heat wire. The statistical approach selected the same optimum sensor locations as the Gaussian integration approach. As a quantitative measure of the fit, the mean squared error between predicted and measured growth are calculated reported in Table 1.

Table 1: Mean Squared Error, Aluminum Tube Tests

\begin{tabular}{|c|c|c|}
\hline Data Set & Statistical $\left(\mu \mathrm{m}^{2}\right)$ & Gaussian $\left(\mu \mathrm{m}^{2}\right)$ \\
\hline 1 & $1.85^{*} 10^{-4}$ & $1.85^{*} 10^{-4}$ \\
2 & $2.58^{*} 10^{-4}$ & $2.58^{*} 10^{-4}$ \\
3 & $5.00^{*} 10^{-4}$ & $5.00^{*} 10^{-4}$ \\
4 & $5.83^{*} 10^{-4}$ & $5.83^{*} 10^{-4}$ \\
5 & $3.23^{*} 10^{-4}$ & $3.23^{*} 10^{-4}$ \\
\hline \hline TOTAL & $18.50^{*} 10^{-4}$ & $18.50^{*} 10^{-4}$ \\
\hline
\end{tabular}


Table 2: Mean Squared Error, Aluminum Tube Tests with Reduced Data Set

\begin{tabular}{|c|c|c|}
\hline Data Set & Statistical $\left(\mu \mathrm{m}^{2}\right)$ & Gaussian $\left(\mu \mathrm{m}^{2}\right)$ \\
\hline 1 & $3.28^{*} 10^{-4}$ & $1.80^{*} 10^{-4}$ \\
2 & $2.65^{*} 10^{-4}$ & $2.52^{*} 10^{-4}$ \\
3 & $5.44^{*} 10^{-4}$ & $4.73 * 10^{-4}$ \\
4 & $5.64^{*} 10^{-4}$ & $5.59 * 10^{-4}$ \\
5 & $2.89 * 10^{-4}$ & $3.19 * 10^{-4}$ \\
\hline TOTAL & $19.90^{*} 10^{-4}$ & $17.83 * 10^{-4}$ \\
\hline
\end{tabular}

To test the robustness of the approach, the size of the data used to fit the model was reduced by selecting every twentieth point. The model was then fit with the smaller data set. For comparison, a statistical approach was used to select the two best temperature measurements. Using the reduced data set, the statistical approach selected different optimum temperature sensors. The performance of the Gaussian model remained approximately the same, while the performance of the statistical model was degraded, as reported in Table 2.

\section{Test Set-Up 2 - Spindle Test Stand}

Nine temperature sensors were placed along the spindle body. The spindle speed was varied from 1000 RPM to 6000 RPM over a 24 hour period. Spindle cycling during the test is plotted in Figure 5. This data was then used to fit the model. To assess the model performance, the model prediction was compared to measured growth of nine sets of independently acquired data.

The observed temperature distribution could be adequately represented by a fifth order polynomial for all boundary conditions, as shown in Figure 4. According to Equation (6), the optimum number of Gaussian integration points is three.

Using three temperature sensors, a comparison of the statistical approach versus the Gaussian integration approach to determine optimum sensor locations was made. The residual mean squared error (difference between model prediction and measured data) for the data used to fit the model was less for the statistical approach. However, when comparing the model prediction to a set of independently acquired measurements not used during the fitting process, the Gaussian integration approach performed better. Furthermore, as less data is used to fit the model, the performance of the statistical approach decreases significantly, while the Gaussian integration approach only slightly decreases. This indicates that the statistical approach requires more data to achieve an adequate fit. 
Table 3: Sum Squared Error

\begin{tabular}{|c|c|c|}
\hline Data Set & Statistical $\left(\mu \mathrm{m}^{2}\right)$ & Gaussian $\left(\mu \mathrm{m}^{2}\right)$ \\
\hline 1 & 2.1150 & 0.9517 \\
2 & 1.7384 & 1.1953 \\
3 & 0.8315 & 0.8641 \\
4 & 0.5247 & 0.8859 \\
5 & 0.6891 & 0.4538 \\
6 & 0.6891 & 2.7146 \\
7 & 5.7754 & 1.4842 \\
8 & 2.3671 & 3.1123 \\
9 & 2.7071 & 1.3786 \\
\hline TOTAL & 19.4347 & 13.0405 \\
\hline
\end{tabular}

As a quantitative number to assess performance, the mean squared error between predicted and measured growth for nine independently acquired data sets was calculated. During the nine tests, spindle speed was varied. Three of the nine tests are plotted in Figures 6 - 8. The mean squared error for each of the nine data sets is reported in Table 3.
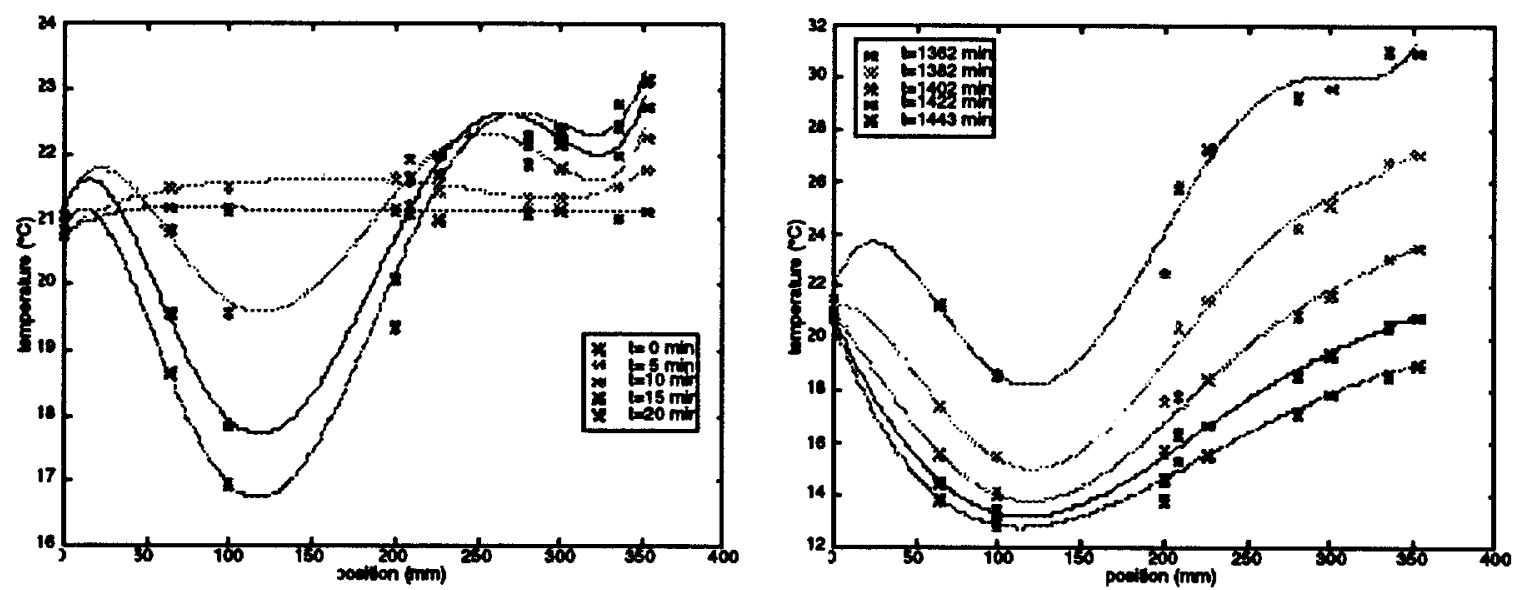

Figure 4: Temperature Profile Across Spindle Length at (a) warm up and (b) cool down 


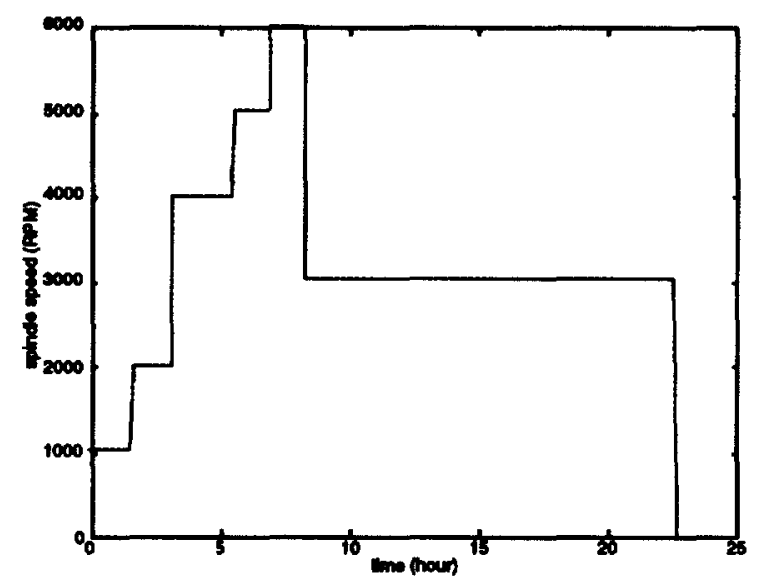

Figure 5: Spindle Cycling During Training

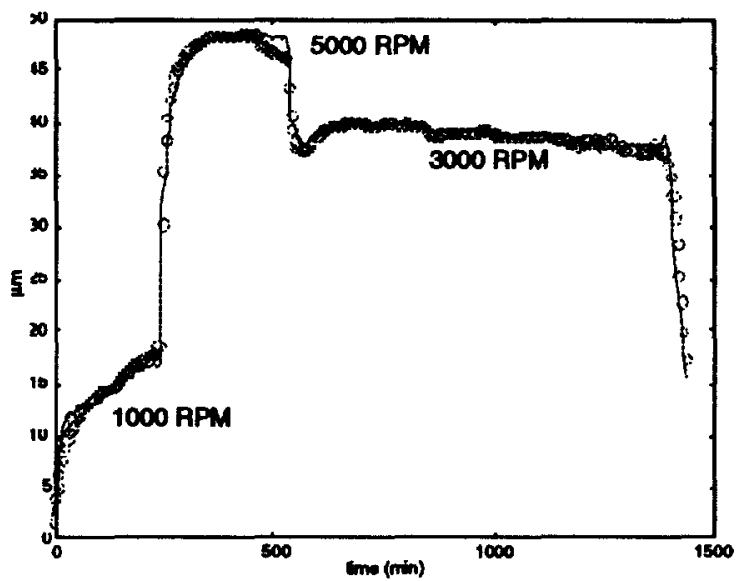

Figure 7: Model Prediction and Measured Axial Growth, Variable RPM

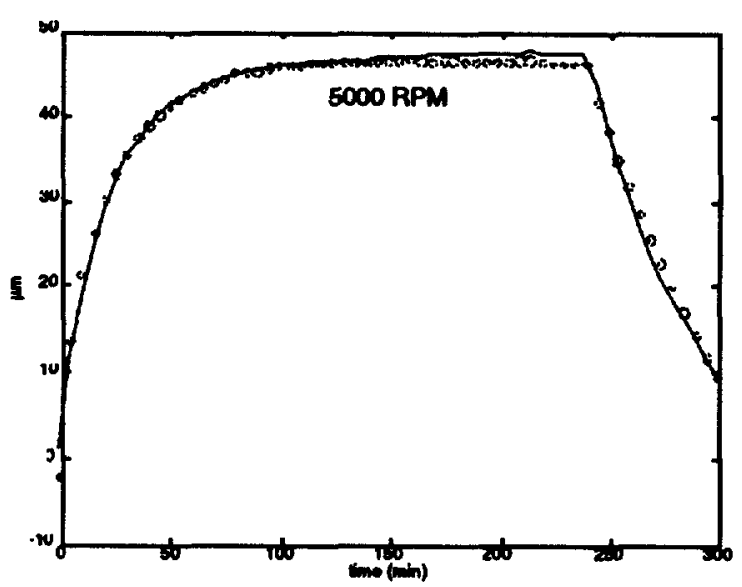

Figure 6: Model Prediction and Measured Axial Growth, Constant RPM

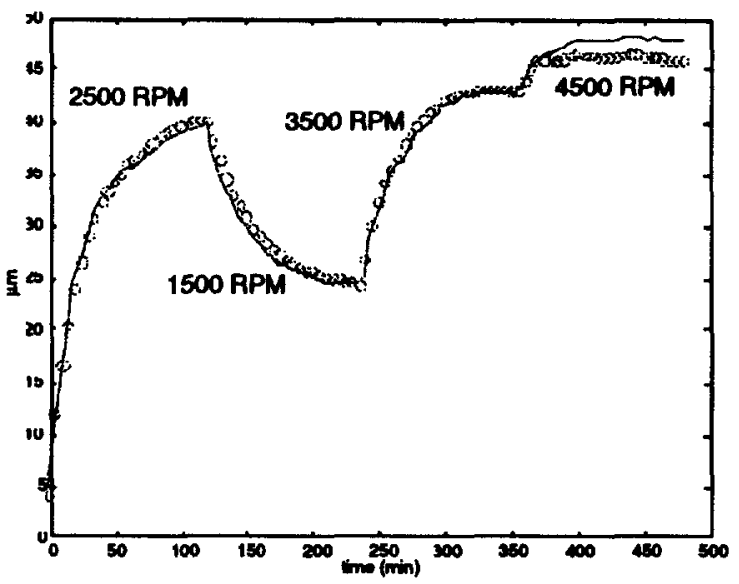

Figure 8: Model Prediction and Measured Axial Growth, Variable RPM

\section{Conclusion}

We have demonstrated that the Gaussian integration approach is a viable method for selecting the optimum temperature locations for the thermal growth model. The approach is robust, performing under a variety of operating conditions. Advantages over statistical approaches include (1) the model is related to the actual physics of the system, (2) the optimum number and location of temperature measurements can be determined without acquiring any data, and (3) less data is required to train the model.

To implement this approach on a machine, we must first determine a method of breaking the machine into individual units. The temperature profile of each unit must be adequately represented by a finite order polynomial. Next we must determine a method to determine the highest order polynomial that can adequately represent the temperature profile under varying operating conditions. This method ideally will not require additional 
temperature measurements. Instead, the polynomial order will be directly related to the location and number of boundary conditions on the individual unit.

\section{References}

1. Balsamo, A.; Marques, D.; Satori, S. (Torino, Italy). A Method for ThermalDeformation Corrections of CMMs. Annals of the CIRP. 1990; Vol. 39(No. 1): pp. 557-560.

2. Chen, J. S.; Chiou, G. (Natl Chung Cheng Univ, Chia-Yi, Taiwan). Quick testing and modeling of thermally-induced errors of CNC machine tools. International Journal of Machine Tools \& Manufacture. 1995 Jul; Vol. 35(No. 7): pp 1063-1074.

3. Chen, J. S.; Yuan, J.; Ni, J.; Wu, S. M. (Univ of Michigan, Ann Arbor, MI, USA). Thermal error modeling for volumetric error compensation. Winter Annual Meeting of the American Society of Mechanical Engineers, Sensors and Signal Processing for Manufacturing American Society of Mechanical Engineers, Production Engineering Division (Publication) PED; Anaheim, CA, USA. New York, NY, USA: ASME; 1992; Vol. 55: pp 113-125.

4. Donmez, M., U.S. Department of Commerce (National Institute of Standards and Technology). Progress Report of the Quality in Automation Project for FY90. Gaithersburg, MD; 1991 Mar; NISTIR 4536.95 pages.

5. Fan, K. C.; Lin, F. F.; Lu, S. S. (Department of Mechanical Engineering, National Taiwan University). Measurement and Compensation of Thermal Error on a Machining Center. Proceedings of the 9th International MATADOR Conference; 1992 Apr.: pp. 261-268.

6. Fraser, S.; Attia, M. Helmi; Osman, M. O. M. (Concordia Univ, Montreal, Que, Can). Modelling, identification and control of thermal deformation of machine tool structures: Part I - concept of generalized modelling. Proceedings of the 1994 International Mechanical Engineering Congress and Exposition Conference, Manufacturing Science and Engineering American Society of Mechanical Engineers, Production Engineering Division (Publication) PED; 1994; Chicago, IL, USA. New York, NY, USA: ASME; Vol. 68-2: pp. 931-944.

7. Fraser, S.; Osman, M. O. M.; Attia, M. H. (Department of Mechanical Engineering, Concordia University, Montreal, Quebec, Canada). Modelling, Identification and Control of Thermal Deformation of Machine Tool Structures: Part II - Generalized Transfer Functions. Proceedings of the 1994 International Mechanical Engineering Congress and Exposition; 1994; Chicago, IL. New York, NY: ASME; vol. 68-2: pp. 945-953. Manufacturing Science and Engineering American Society of Mechanical Engineers, Production Engineering Division PED).

8. Hardwick, B. R. (Advanced Manufacturing Technology Research Institute, Macclesfield). Improving the Accuracy of CNC Machine Tools Using Software Compensation for Thermally Induced Errors: pp. 269-275.

9. Hatamura, Y.; Nagao, T.; Mitsuishi, M.; Kato, K.; Taguchi, S.; Okumura, T.; Nakagawa, G.; Sugishita, H. (Univ of Tokyo, Tokyo, Jpn). 
Development of an intelligent machining center incorporating active compensation for thermal distortion. CIRP Annals. 1993; Vol. 4(No. 1): pp 549-552.

10. Janeczko, J. (Giddings and Lewis Machine Tool). Machine Tool Thermal Distortion Compensation. 4th Biennial International Manufacturing Technology Conference; 1988 Sep 7; Chicago, IL; Session 7D: Precision Metrology: pp. 7-167 thru 7-181.

11. Jedrzejewski, J.; Kaczmarek, J.; Kowal, Z.; Winiarski, Z. Numerical Optimization of Thermal Behaviour of Machine Tools. Annals of the CIRP. 1990; Vol. 39(No. 1): pp. 379-382.

12. Jedrzejewski, J.; Modrzycki, W. (Wroclaw Technical Univ, Pol). New approach to modelling thermal behaviour of a machine tool under service conditions. CIRP Annals 1992; Vol. 41(No. 1): pp 455-458.

13. Lo, Hhih-Hao; Yuan, Jingxia; Ni, Jun (S.M. Wu Manufacturing Research Laboratory, Department of Mechanical Engineering and Applied Mechanics, The University of Michigan, An Arbor). Optimal Modeling of Thermal Error Components for Machine Tool Error Compensation; 1994; Vol. 1.

14. McClure, R., LLNL. Thermally Induced Errors. Weck, M.; Petuelli, G., Technical University of Aachen. Technology of Machine Tools. 1980 Oct; Vol. 5, Machine Tool Accuracy: pp. 9.6-1 - 9.6-23.

15. Moriwaki, T. (Kobe University). Thermal Deformation and Its On-Line Compensation of Hydrostatically Supported Precision Spindle. Annals of the CIRP. 1988; Vol. 37(No. 1): pp. 393-396.

16. Moriwaki, T.; Zhao, C., The Faculty of Engineering (Kobe University, Japan). Neural Network Approach to Identify Thermal Deformation of Machining Center. Proceedings of the 8th International IFIP TC5-WG5.3 Conference, Human Aspects in Computer Integrated Manufacturing; 1992. North Holland: Elsevier Science Publishers B.B.: pp. 685-697.

17. Sartori, S. (Turin, Italy). A Method for the Identification and Correction of Thermal Deformations in a Three Coordinate Measuring Machine. VDI Berichte. 1989; Vol. 761: pp. 185-192.

18. Sartori, S.; Zhang, G. (Institute of Metrology, Italy; University of Tianjin, China). Geometric Error Measurement and Compensation of Machines. Annals of the CIRP. 1995; Vol. 44(No. 2): pp. 1-11.

19. Schalz, K. J. Improved Thermal Error Compensation (TEC) of CMM's. VDI Berichte. 1989; Vol. 761: pp. 177-184.

20. Schmidt, J.; Minges, R. Thermal Displacements at Machine Tools Part 2:

Measurements and Possible Compensation on a 3-Axial NC Milling Machine. Werkstattstechnik Zeitschrift Fur Industrielle Fertigung. 1990 Oct; Vol. 80(No. 10): pages 577-580. 
21. Soons, J.; Spaan, H.; Schellekens, P., Precision Engineering Group (Eindhoven University of Technology, The Netherlands). Thermal Error Models for Software Compensation of Machine Tools. ASPE Proceedings, Annual Meeting; 1994 Oct; Cincinnati, OH: pp. 69-75.

22. Soons, J.; Theuws, F.; Schellekens, P. (Eindhoven University of Technology). Modeling the Errors of Multi-Axis Machines: A General Methodology. Precision Engineering. 1992 Jan; Vol. 14(No. 1): pp. 5-19.

23. Spur, G.; Hoffmann, E.; Paluncic, Z.; Benzinger, K.; Nymoen, H. (Institut für Werkzeugmaschinen und Fertigungstechnik, TU Berlin/Federal Republik of Germany). Thermal Behaviour Optimization of Machine Tools. Annals of the CIRP. 1988; Vol. 37(No. 1): pp. 401-405.

24. Srinivasa, N.; Ziegert, J.; Smith, S. (Department of Mechanical Engineering, University of FL, Gainesville). Prediction of Positional Errors of a Three Axis Machine Tool Using Neural Network. Japan / USA Symposium on Flexible Automation, ASME. 1992; Volume 1: pp. 203-209.

25. Srinivasa, N.; Ziegert, J. (Department of Mechanical Engineering, University of FL). Real-Time Learning of Thermal Errors in Machine Tools Using a Fuzzy Logic Based Neural Network: pp. 1-6.

26. Srivastava, A. K.; Veldhuis, S. C.; Elbestawit, M. A. (McMaster Univ, Hamilton, Ont, Can). Modelling geometric and thermal errors in a five-axis CNC machine tool. International Journal of Machine Tools \& Manufacture. 1995 Sep; Vol. 35(No. 9): pp 1321-1337.

27. Veldhuis, S. C.; Elbestawi, M. A. (McMaster Univ, Hamilton, Ont, Can). Modeling and compensation for five-axis machine tool errors. Proceedings of the 1994 International Mechanical Engineering Congress and Exposition Conference, Manufacturing Science and Engineering American Society of Mechanical Engineers, Production Engineering Division (Publication) PED; 1994; Chicago, IL, USA. New York, NY, USA: ASME; Vol. 68-2: pp 827-839.

28. Veldhuis, S.; Elbestawi, M., Intelligent Machines and Manufacturing Research Center (Dept. of Mechanical Engineering, McMaster University, Hamilton, Canada). A Strategy for the Compensation of Errors in Five-Axis Machining. Annals of the CIRP. 1995 Jan; Vol. 44(No. 1): pp. 373-377.

29. Venugopal, R.; Barash, M. (Purdue University). Thermal Effects on the Accuracy of Numerically Controlled Machine Tools. Annals of the CIRP. 1986; Vol. 35(No. 1): pp. 255-258.

30. Yang, S.; Yuan, J.; Ni, J. (S. M. Wu Manufacturing Research Center, The University of Michigan, Ann Arbor, MI). The Improvement of Thermal Error Modeling and Compensation on Machine Tools by CMAC Neural Network. International Journal of Machine Tools and Manufacture. 1996 Apr; Vol. 36(No. 4): pp. 527-537. 
31. Ziegert, John C.; Kalle, Prashant (Univ of Florida, Gainesville, FL, USA). Error compensation in machine tools: A neural network approach. Journal of Intelligent Manufacturing. 1994 Jun; Vol. 5(No. 3): pp 143-151. 


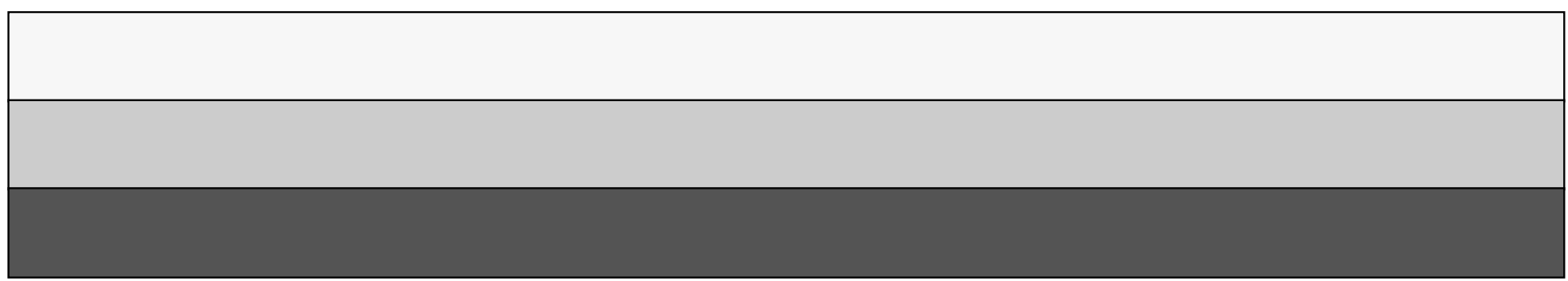

